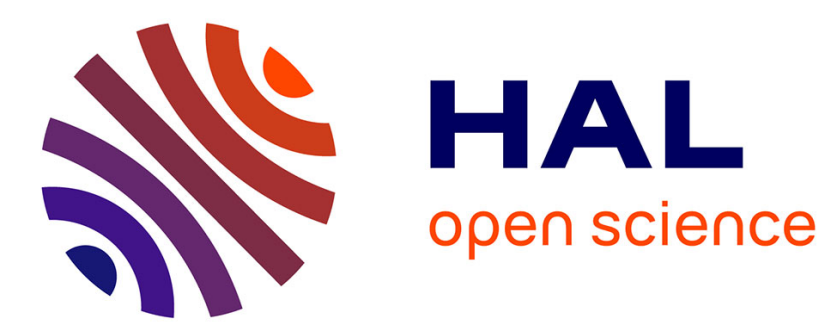

\title{
RADIATION DAMAGE AND STRUCTURAL LATTICE DEFECTS
}

\author{
G. Vogl
}

\section{To cite this version:}

G. Vogl. RADIATION DAMAGE AND STRUCTURAL LATTICE DEFECTS. Journal de Physique Colloques, 1974, 35 (C6), pp.C6-165-C6-180. 10.1051/jphyscol:1974615 . jpa-00215765

\section{HAL Id: jpa-00215765 https://hal.science/jpa-00215765}

Submitted on 1 Jan 1974

HAL is a multi-disciplinary open access archive for the deposit and dissemination of scientific research documents, whether they are published or not. The documents may come from teaching and research institutions in France or abroad, or from public or private research centers.
L'archive ouverte pluridisciplinaire HAL, est destinée au dépôt et à la diffusion de documents scientifiques de niveau recherche, publiés ou non, émanant des établissements d'enseignement et de recherche français ou étrangers, des laboratoires publics ou privés. 


\title{
RADIATION DAMAGE AND STRUCTURAL LATTICE DEFECTS
}

\author{
G. VOGL
}

Physik-Department, Technische Universität München, D-8046 Garching, Germany

\begin{abstract}
Résumé. - Ce mémoire est consacré aux influences sur les études Mössbauer des défauts de structure des réseaux, principalement dans les métaux, et réciproquement aux informations que l'on peut obtenir sur ces défauts à partir d'études Mössbauer.

On commence par une courte mise au point sur l'état actuel des connaissances sur la production de défauts dans les processus de collision de particules d'énergie très grande (implantation «externe » et « interne ») et dans les réactions nucléaires. On passe aussi en revue la migration des défauts conduisant à des réactions de défaut ainsi que le revenu dans des expériences en ligne et des expériences mettant en œuvre des périodes radioactives longues. Après une comparaison des différentes méthodes d'étude de défauts structuraux de réseaux, on discute l'aspect particulier des informations que seules peuvent donner des méthodes microscopiques tels que l'effet Mössbauer et des méthodes apparentées. Dans la seconde partie du mémoire, on démontre, par l'examen d'expériences Mössbauer sur les défauts de structure, l'influence mutuelle des études de défauts et Mössbauer. Les exemples peuvent être divisés en deux groupes : 1. «Dommage en corrélation 》. 2. «Dommage sans corrélation 》 suivi du piégeage des défauts par des impuretés Mössbauer. On présente des commentaires sur les résultats d'expériences variées. Finalement on décrit plus en détail une expérience récente. Dans celle-ci des impuretés de $\mathrm{Co}^{57}\left(\mathrm{Fe}^{57}\right)$ dans l'aluminium piègent au cours de leur migration des défauts interstitiels produits par irradiation de l'aluminium à basse température, ce qui permet une étude microscopique des interstitiels en utilisant les atomes de $\mathrm{Co}^{57}\left(\mathrm{Fe}^{57}\right)$ comme micro-sondes.
\end{abstract}

\begin{abstract}
The paper is concerned with influences of structural lattice defects mainly in metals on Mössbauer studies and contrary-wise with the information about these defects available from Mössbauer studies.

First a short review of present knowledge about the production of defects in collision processes of highly energetic particles (« external» and « internal» implantation) and in nuclear reactions is given. Defect migration leading to defect reactions and annealing in on-line experiments and in experiments involving long radioactive half-life is reviewed as well. After a comparison of different methods of studying structural lattice defects, the particular information uniquely available from microscopic methods as the Mössbauer effect and related methods is discussed. In the second part of the paper the mutual influence of defects and Mössbauer studies is demonstrated in a survey of defect relevant Mössbauer experiments. The examples can be divided into two groups : 1 . «Correlated damage »;2. «Uncorrelated damage » followed by trapping of the defects at Mössbauer impurities. Comments concerning the results of various experiments are presented. Finally a recent experiment is discussed in greater length. In this experiment $\mathrm{Co}^{57}\left(\mathrm{Fe}^{57}\right)$ impurities in aluminum trap interstitials produced by low-temperature irradiation in aluminum during the interstitials migration, thus permitting the microscopic investigation of the interstitials with the $\mathrm{Co}^{57}\left(\mathrm{Fe}^{57}\right)$ atoms as microprobes.
\end{abstract}

1. Introduction. - This paper will be concerned with the interaction of structural lattice defects (in the following abbreviated SLD) in solids and the Mössbauer effect (abbreviated ME). We will try to discuss on the one hand the influence which SLD may have on Mössbauer spectra, on the other hand the contribution that $\mathrm{ME}$ investigations can make to illuminate problems of SLD in solids.

SLD are defects in the regular construction of a crystal or a crystalline grain. They may be point defects, as vacancies and interstitial atoms, or moredimensional defects (as e. g. dislocations, grain boundaries or larger agglomerates). We shall deal mainly with the production of SLD by irradiation, the socalled radiation damage, since radiation defects are those SLD which are by far the most frequently interacting with ME investigations. This again means that our accent will be on point defects and their agglomerates (caused by the point defects' diffusion, etc.), since irradiation knocks out single atoms.

In 1971 Schroeer, Lambe and Spencer [1] presented a short review of the state of the field at that time discussing ME investigations influenced by defects in all types of solids. In the same year Gonser [2] and De Waard [3] at the Vienna IAEA panel on Mössbauer spectroscopy and its applications gave summaries on various aspects of defects in solids and Wertheim [4] reviewed studies of crystalline defects by the Mössbauer effect covering the whole field of defects in various types of solids. We shall attempt to treat here a more limited field, but in more detail. We will mainly discuss structural lattice defects as produc- 
ed by elastic collisions and will hardly deal at all with the consequences of the ionizing action of irradiation and " after effects" of the radioactive decay. Thus we will concentrate on SLD in metals (where the latter effects are of minor importance). We think this limitation to be justified by the fact that ME studies of SLD in metals may claim the widest interest and are easiest to be interpreted. Thus they are a basis for understanding more difficult systems. Defects in elementary semiconductors will be shortly discussed, too.

The ME is extremely well suited for the investigation of «microscopic » defect properties. By «microscopic» we mean that the hyperfine parameters to be determined from a Mössbauer spectrum and the Debye-Waller factor are particularly sensitive for the local conditions at the Mössbauer atom's site and in its immediate environment. Under favorable conditions each definite lattice site provides its special component to the Mössbauer spectrum. The ME is therefore also capable of providing microscopic information about defects in this region (« locally correlated» defects). Such information is not obtainable from integral ( « macroscopic ») methods, as e. g. the electrical resistivity which is till now the most applied method for studying SLD in metals.

Local correlation of Mössbauer atom and SLD is important for ME/SLD studies. We shall attempt to classify all ME applications on SLD problems into two groups :

a) «Correlated creation » of SLD and Mössbauer atom.

b) Production of Mössbauer atoms as impurities in the host and of the SLD in separate processes. Subsequent migration of the SLD leads to local correlation by " trapping » of the SLD at the Mössbauer impurity atoms.

In Section 2 we will give a short survey on the various types of SLD in solids (mainly metals), on their production and reaction processes. Section 3 will compare the various methods for SLD studies and discuss what type of new information might be obtained from ME studies. In Section 4 we will discuss examples of ME investigations concerned with SLD. In Section 5 we will try to indicate the directions into which in our opinion future ME-SLD activities will or should proceed.

2. Structural lattice defects in solids. - $2.1 \mathrm{PRO}^{-}$ DUCTION OF STRUCTURAL LATTICE DEFECTS IN SOLIDS (MAINLY BY IRRADIATION). - In this section we shall deal with the following situation. Imagine a lattice where the defects are frozen-in immediately after their production, so that they have no opportunity to diffuse or undergo reactions. This condition is normally fulfilled, if the solid is kept at liquid helium temperature.

There are surveys on SLD production by highly energetic particle irradiation in metals $[5,6,7]$ and in semiconductors $[8,9]$ and also on SLD production in metals by implantation [10] so we can restrict our selves to a short survey $\left({ }^{1}\right)$.

\subsubsection{Collision processes of highly energetic particles.} - Highly energetic electrons (kinetic energy $E$ greater than a few hundred $\mathrm{keV}$ ), fast neutrons ( $E$ greater than a few hundred $\mathrm{eV}$ ), highly energetic light ions (protons, deuterons, $\alpha$-particles) or heavy ions can all interact with lattice atoms by elastic collisions which can cause the displacement of the lattice atoms. The maximum transferred energy in a collision is

$$
E_{\max }=\frac{4 m_{1} \cdot m_{2}}{\left(m_{1}+m_{2}\right)^{2}} \cdot E
$$

where $m_{1}$ is the mass of the irradiation particle and $m_{2}$ the mass of the knock-on atom.

Take as an example an aluminum lattice. Electrons with kinetic energies higher than a threshold energy of about $0.2 \mathrm{MeV}$ will transfer enough energy to the atoms in collisions to produce damage, the damage rate increases with increasing energy. Near the threshold energy only one or a few point defects are produced per incident electron; the defect structure in this case is extremely simple. At higher electron energies the primary knock-on atom can receive enough energy so that it can produce further knock-on atoms and a displacement cascade will arise (Fig. 1).
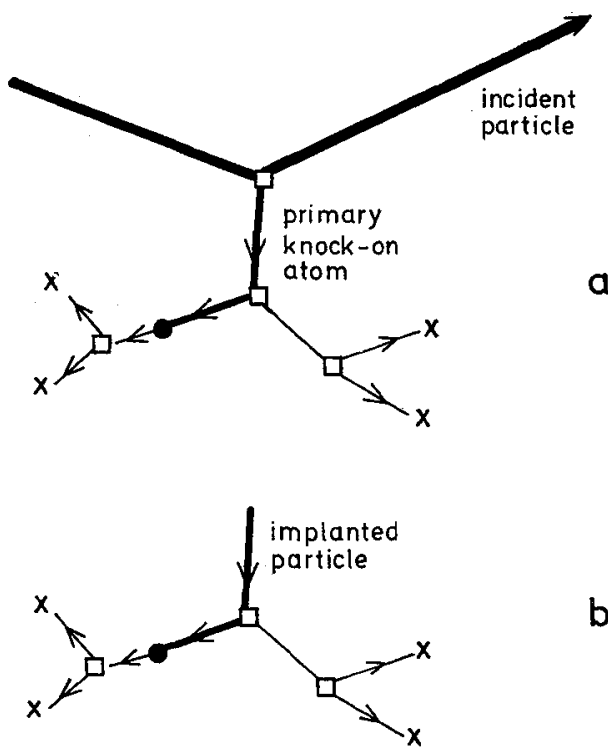

b)

FIG. 1. - Schematic comparison of collision cascades : a) irradiation with highly energetic particle, $b$ ) implantation. $\times$ interstitial, $\square$ vacancy, - possible final position of primary knock-on or implanted particles.

(1) Vacancies can also be produced by quenching a sample from high temperature. Vacancy concentrations of the order of $10^{-4}$ [11] can be obtained. The relevance for $\mathrm{ME}$ experiments and vice versa is still rather small, but as will be discussed in Section 4.2 there is some chance to study quenched vacancies with the ME. 
This is then similar to fast neutron irradiation in a nuclear reactor. Since in the reactor neutron spectrum the fast neutrons have energies of the order of $1 \mathrm{MeV}$, the primary knock-on atom will usually receive a high kinetic energy.

The path of the primary knock-on atom through the lattice will therefore be similar to that of a charged irradiation particle (proton, deuteron or $\alpha$-particle) or an ion in implantation or Coulomb excitation experiments. The recoil process of a primary host atom might even be called «internal implantation ». Therefore, we can now discuss all these processes together.

If the kinetic energy of the particle (primary or implanted ion) is much higher than a certain threshold energy which is very roughly [12]

$$
E_{\mathrm{i}} \simeq A \mathrm{keV}
$$

where $A$ is the mass number of the particle, then the particle will not primarily undergo elastic collisions with lattice atoms, but lose its kinetic energy mainly by the excitation of electrons (ionization). Robinson and Torrens [13] have given a more detailed description of the distribution of the energy loss into radiation damage and electronic excitation using Lindhards's calculations [14]. Robinson's diagram showing the « damage efficiency » is given in figure 2 .

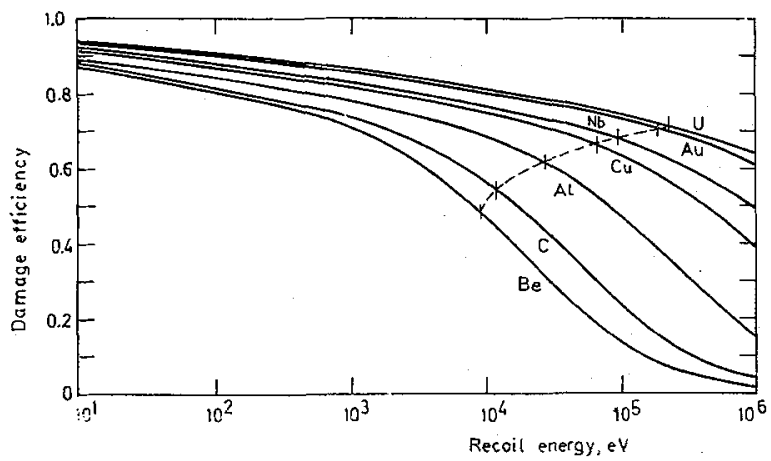

FIG. 2. - Proportion of recoil energy available for atomic displacements (damage efficiency). After Robinson [7]. Broken line : Rule of thumb : $E_{\mathrm{i}} \simeq A \mathrm{keV}$.

In metals ionization processes will lead to no permanent radiation damage since damage in the electronic structure «anneals» spontaneously. After having slowed down below $E_{\mathrm{i}}$, the moving ion and the lattice ions may be regarded in the simplest picture as interacting via hard-sphere elastic collisions. According to the 20-year old model of Kinchin and Pease [15] the average number of Frenkel pairs created by an atom of energy $E$ (a Frenkel pair is a pair of vacancy and interstitial atom) will then be

$$
\bar{v}(E)=\frac{E}{2 E_{\mathrm{d}}},
$$

where $E_{\mathrm{d}}$ is the minimum displacement energy necessary to create just one stable Frenkel pair. For most metals it is of the order of 20 to $40 \mathrm{eV}[16,17]$.
Robinson and Torrens [13] have recently performed a thorough study of the atomic displacement process with a more realistic model (Molière potentiel). Taking

$$
\bar{v}(E)=\frac{\kappa \cdot\left(E-E_{\mathrm{in}}\right)}{2 E_{\mathrm{d}}}
$$

with $\kappa$ the displacement efficiency and $E_{\text {in }}$ the energy lost in the cascade through inelastic processes, they find for copper, iron and gold for knock-on atom energies between $10 \mathrm{keV}$ and $100 \mathrm{keV}: \kappa=0.8$ to 0.9 and $E_{\mathrm{in}} / E=(10$ to 30$) \%$. These results do not deviate too much from the results of the simple Kinchin-Pease model.

Before being finally stopped, the moving atom loses its kinetic energy by performing subsequent collisions in rather short distances of the order of a few atomic spacings. Vineyard's group (Gibson et al. [18], Erginsoy et al. [19, 20]) and Beeler [21] in the early 1960s and Robinson and Torrens [13] quite recently have made computer simulations of the damage which an incident particle creates in a f. c. c. or b. c. c. lattice transferring up to $100 \mathrm{keV}$ to the primary knock-on atom. Figure 3 show a $1 \mathrm{keV}$

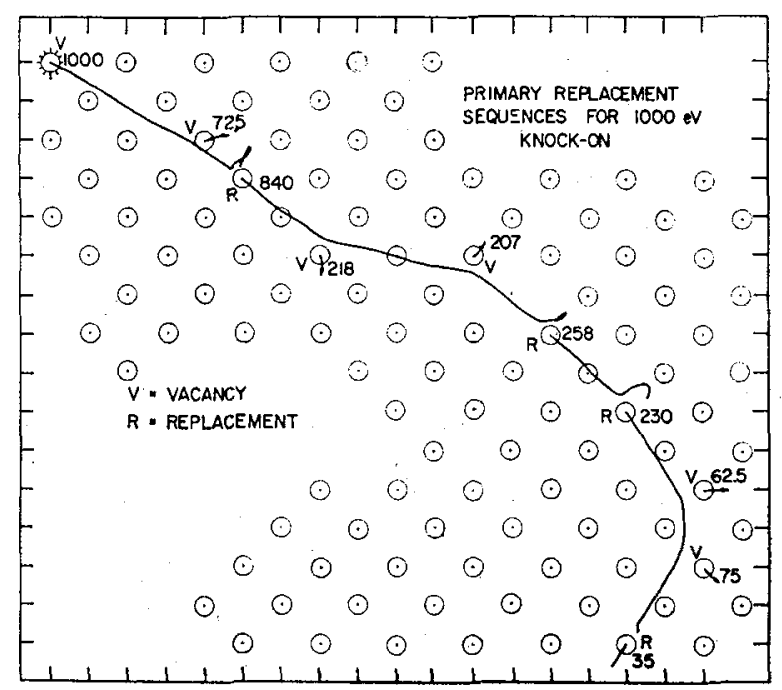

FIG. 3. - Computer simulation of primary replacement sequence associated with a $1 \mathrm{keV}$ knock-on in $\alpha$-iron. The numbers indicate the kinetic energies of the atoms. After Erginsoy et al. [20].

collision cascade from Erginsoy's calculations and figure 4 a $5 \mathrm{keV}$ cascade from Beeler'swork.

From the figures it can be seen that a knock-on particle generally does not run a very long way. After a few collisions it performs a replacement collision and remains in a rather unperturbed environment, eventually in the vicinity of a vacancy. The kinetic energy continues to be transferred to further atoms and at the end of the cascade there may be a region which is rather rich in vacancies, a so-called « depleted zone » [22]. One should not forget that the vacancy density in such a zone is small, it is not at all a cavity. 


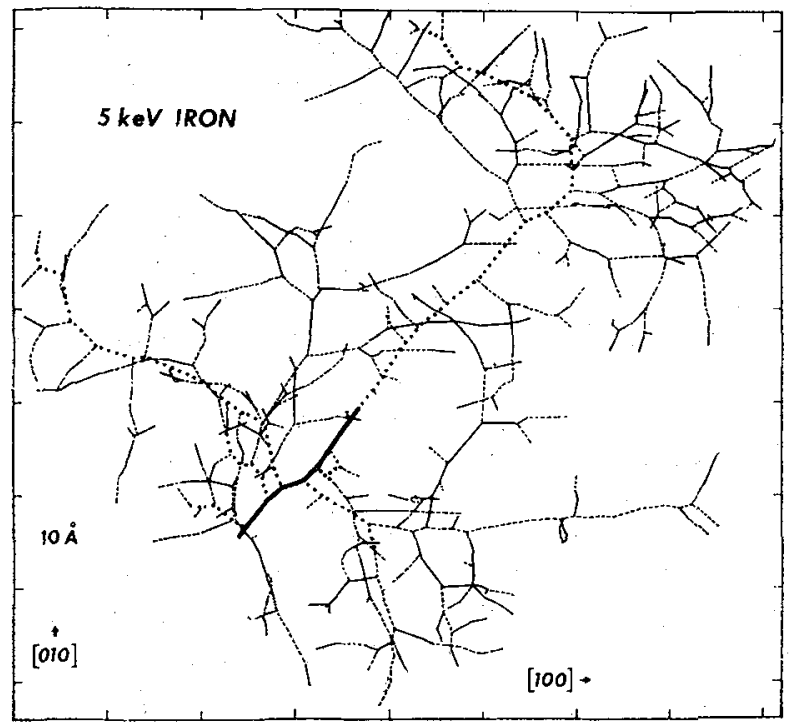

FIG. 4. - Computer simulation of displacement cascade produced by $5 \mathrm{keV}$ iron atom in $\alpha$-iron. Projection on $(001)$ plane. After Beeler [21].

Holmes [23] has already demonstrated that the famous first picture of Brinkman [24] of a « displacement spike » which looked like a cavity on his figures could not berc alistic. For copper atoms as primary knock-ons in a fission reactor spectrum receiving $64 \mathrm{keV}$ kinetic energy, Holmes estimated a cigar-shaped cascade region $250 \AA$ long and $100 \AA$ wide including 100000 atoms. According to the Kinchin-Pease model 1400 Frenkel pairs would be created so that the defect density would be 1 to 2 percent. Some of the interstitials will certainly be within the «instability volume » of a vacancy so that they will recombine immediately by spontaneous recombination and the final defect density will be even lower. Recent computer calculations of the defect density in a cascade and of the short-term annealing within the cascade have been performed by Doran and by Doran and Burnett [25] and by Robinson and Torrens [13], confirming in general Holme's picture. Recent diffuse X-ray scattering experiments by v. Guerard [26] also show that the vacancy density in a cascade cannot exceed a few percent.

Unfortunately, it appears difficult to say much more about the exact structure of the « zones » and on the interstitials' distance from the vacancies. It is possible that focussing collisions or «dynamic crowdions» i. e. energy and mass transport along close-packed lattice directions could greatly separate the interstitials from the vacancies. It is, therefore, difficult to make exact predictions on radiation damage influence in $\mathrm{ME}$ measurements after implantation (external or internal). But one can conclude that contrary to what one might expect at first glance there will rarely be extremely heavy damage in the implanted particle's immediate vicinity.

The elementary semiconductors diamond, silicon, germanium, $\alpha$-tin have diamond lattice structure and covalent bonding. Because of this type of bonding unlike the metals, not only elastic collisions can create radiation damage, but also ionization leading to bond rupture. Another important difference is that : whereas in metals only the geometric structure of a point defect is important in determining the defect type (there are vacancies and possibly various types of interstitials) in the semiconductors the various possible charge states of the SLD represent a second determining parameter. For instance, there are presumably singly positive, neutral, singly negative and doubly negative vacancies. Although a large collection of data exists on point defects, the knowledge about the defects is therefore still rather fragmentary.

2.1.2 Defect-production in nuclear reactions. - This field is especially interesting for $\mathrm{ME}$ investigations since oftèn the Mössbauer nucleus or its parent nucleus is produced or excited by a nuclear reaction directly in the host lattice. Thus, in this case one must nearly always be concerned with SLD. The nuclear reactions may be e. g. $(n, \gamma)$ reactions or $(d, p)$ reactions.

An advantage of the $(n, \gamma)$ processes is that due to the low transmitted energy [27] simple defect structures will be produced.

Computer simulations of Vineyard's group [18, 20] predict that at low kinetic energies of the colliding particle, replacement collisions in close packed lattice directions are most probable. ME studies have experimentally confirmed these prediction from computer simulations [27-29].

2.2 Migration, REACTIONS AND ANNEALING OF STRUCTURAL LATTICE DEFECTS. - Up to now we have regarded the defects as being immediately frozen into their places after production. We will now study defect migration at increased temperature after the end of the irradiation (《 annealing »).

On their migration path through the lattice the defects can either meet a defect of opposite type (vacancy-interstitial) or another sink and anneal by recombination, or they can meet a defect of same type or an impurity atom to form together a complex (a cluster). The complex can be much more stable and can break-up and anneal at a much higher temperature, sometimes even at the temperature of self-diffusion. A schematic representation of the consequences of defect migration in a metal is given in figure 5 .

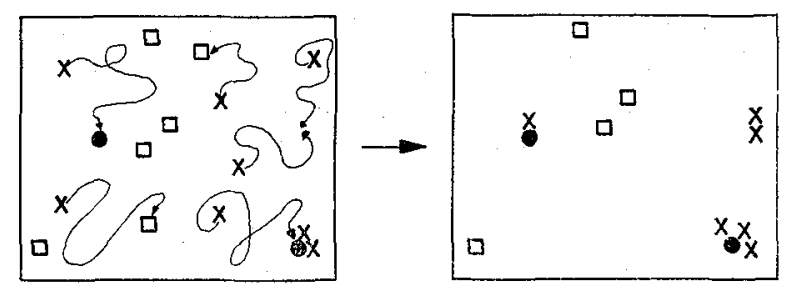

FIG. 5. - Schematic representation of the consequences of interstitial migration in a metal. $x$ interstitial, $\square$ vacancy, - impurity atom. 
The change in time of the concentration $c$ of a simple type of defect by migration and subsequent reaction with some other type of defect («a sink ») is (see e. g. [6])

$$
\frac{\mathrm{d} c}{\mathrm{~d} t}=-F(c) \cdot v \cdot \exp \left(-\frac{E_{\mathrm{m}}}{k T}\right) .
$$

Here $v$ is the lattice vibration frequency $\left(\simeq 10^{12} / \mathrm{s}\right)$. $E_{\mathrm{m}}$ the activation energy for the defect's migration, and $F(c)$ some function of $c$ which also includes an entropy factor of the process and a radius for the reaction of defects and sinks. $F(c)$ is proportional to $c$ if the number of sinks where the defect's migration ends greatly exceeds the defect number, or if every defect has exactly one defect of opposite type in its immediate neighbourhood to recombine or react with it (e. g. close Frenkel pair recombination). Then we have a «first-order reaction ». If, on the other hand, e. g. the migrating defect has to seek a defect of the opposite type on a random walk through the lattice and there is about an equal number of the opposite defects, then the concentration will enter as $c^{2}$ into $F(c)$. This is a «second-order reaction» (e. g. : free migration of irradiation produced interstitials to an equal number of simultaneously produced vacancies).

The study of annealing with macroscopic methods is devoted to the identification of the types of defects and the reactions involved during annealing by determining the order of the reaction (the exponent of $c$ ) and the migration energy $E_{\mathrm{m}}$.

Figure 6 gives residual resistivity measurements during gradual isochronal annealing of aluminum and

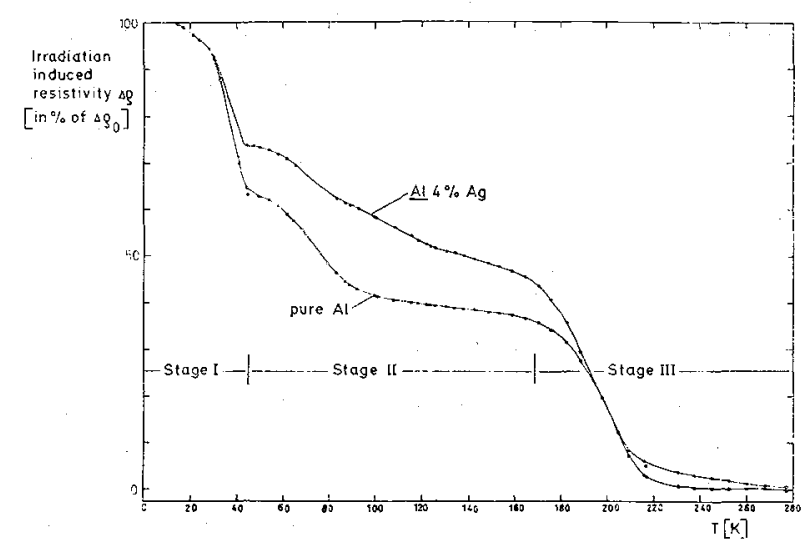

FIG. 6. - Change of the residual electrical resistivity during isochronal annealing of aluminum and an aluminum alloy irradiated at $4.6 \mathrm{~K}$ with $3.2 \times 10^{18}$ fast neutrons $/ \mathrm{cm}^{2} . \Delta \rho_{0}$ is the total resistivity increase by irradiation. After Riess and Vogl [30].

an aluminum alloy after fast neutron irradiation at 4.6 K [30]. Since the electrical resistivity is a good measure for the defect concentration (see Section 3), these curves indicate defect disappearance by annealing. «Stage » $I$ is generally ascribed to interstitial migration leading to recombination with vacancies or (as in case of alloys) to the formation of interstitial-impurity clusters preventing interstitial recombination with vacancies. Therefore, the irradiation induced residual resistivity after stage $I$ is higher in the alloys than in the pure aluminum. "Stage » II is ascribed to the dissolution and new formation of clusters. "Stage " III is probably due to vacancy migration leading to the disappearance of the remaining vacancies at various types of sinks. The appearance of annealing stages is a general feature of all metals, in f. c. c. metals they resemble more or less the stages in aluminum [31].

Unfortunately, the pure situation (just one type of defect migrating to exactly one type of other defect) is seldom realized. Especially for room temperature irradiation we always have to deal with a number of reactions at the same time. This statement underlines the advantage of low-temperature irradiations followed by controlled successive gradual heat treatment of the sample, so that the various defects begin to migrate one after the other in order of increasing activation energy. But even then the defects of one single type will migrate to various different types of sinks to anneal or form agglomerates so that again the situation is complicated.

In metals the self-interstitials (interstitial atoms of host type) have activation energies for migration of the order of 0.1 to $0.3 \mathrm{eV}$. These values are sufficiently low so that even in on-line experiments with only a few nsec elapsing between the creation of the defects and the measurement, interstitials can anneal at or even below room temperature.

In experiments (not of on-line type) where more time elapses between defect creation and the measurement (e. g. isotope separator implantation), controlled temperature treatments are possible and the kinetics of defect reactions can be studied. Generally the experimentalist will perform heat treatments with a duration of the order of minutes. Then interstitials in aluminum, copper or iron migrate between about 35 and $80 \mathrm{~K}$. An illuminating diagram showing the relation between heating-time and heating temperature to reach the same effect in defect annealing has been given by De Waard at the Uppsala Conference, 1974 [32].

For vacancy diffusion the activation energies are much higher. For metals they are of the order of 0.6 to $1.4 \mathrm{eV}$ [33]. Thus, even during heat treatment of the order of minutes there will be no vacancy migration below about $180 \mathrm{~K}$ or even room temperature.

Finally a few words should be said regarding the «thermal spike " at the end of a collision cascade. Noticable energy dissipation to many atoms can be expected in this region and one can attempt to look at this phenomenon as «heating-up » of that region. According to Thompson [6] for a kinetic energy of the incident particle of $40 \mathrm{keV}$ the «temperature» increase in a spike of diameter $200 \AA$ in a metal may be estimated to be $1300 \mathrm{~K}$, this being an upper limit. The «temperature " in the spike will decrease with a relaxation 
time which Thompson estimated from classical theory of heat conduction : $t_{\mathrm{R}} \simeq 10^{-12} \mathrm{~s}$ to $10^{-11} \mathrm{~s}$. Thompson [6] estimates that the time during which the spike is sufficiently «hot " is so short that only defects with $E_{\mathrm{m}} \ll 0.6 \mathrm{eV}$ can migrate in the spike. This excludes vacancy migration, but would eventually enable interstitial migration, leading to some annealing and clustering. Thompson admits that we do not know enough about spike parameters to make substantial predictions on these processes.

In the elementary semi-conductors the activation energy for defect migration depends on the defect's charge. There is, for example, a different activation energy for the migration of a neutral and double negatively charged vacancy. Collections of suggested values have been given by Seeger and coworkers [9]. They show up large discrepancies still existing between various interpretations.

3. Information about structural lattice defects from various methods. - 3.1 COMPARISON OF DIFFERENT METHODS FOR DEFECT STUDIES IN VARIOUS TYPES OF soliDs. - The ME with the Mössbauer atom sitting as a probe in the lattice offers information about the probe's local (microscopic) surrounding. Therefore we call it a « microscopic » method. Compared with other microscopic methods such as optical absorption or EPR it has the advantage that the nuclear $\gamma$ radiation penetrates substances which are unsuited for those methods. We will now compare various methods of studying SLD in various types of solids.

Defects in ionic crystals ( Colour Centers ») have been studied since about half a century. A rather completed picture has been achieved. The investigations were done on the one hand with «macroscopic» or «integral » methods, i. e. studying macroscopic property changes as e. g. lattice parameter or length changes on irradiation, but also with microscopic methods as optical and EPR measurements. These latter methods provide for instance information on electron charge at the defects. Thus, in ionic crystals there seems to be not so much need for another microscopic method as the ME.

The situation is similar in the elementary semiconductors (mainly in silicon and germanium). A considerable number of infrared absorption and EPR studies on irradiated samples and also of channeling studies of implanted crystals has provided microscopic information on point defects. However, since the number of possible types of point defects is rather high, there are still many open problems [9]. ME investigations can be expected to give some important additional information to shed more light on these problems.

Investigations of SLD in metals began to mushroom with the development of nuclear reactors. These were until recently nearly all investigations of integral property changes (with macroscopic methods) : Measurements of electrical resistivity changes are by far the most frequent studies, besides changes of mechanical properties, length and lattice parameter changes, stored energy, etc. were measured. Measurements of the electrical resistivity provide an excellent and very sensitive method to study the relative overall concentration of SLD. If the contribution of one Frenkel pair (one pair of vacancy and interstitial) to the electrical resistivity can be estimated by a combination of various integral methods, even the absolute overall defect concentration can be determined. As explained in the preceding section and to be seen from figure 6 , by gradual heating after irradiation various defect reactions can be separated and the influence of impurity atoms on these reactions can be studied.

But all of the integral methods can hardly give information on what is going on at the defect's site on a microscopic scale. Because of the metals' high conductivity and their opacity to light, EPR or optical studies, i.e. microscopic investigations as with the alkali halides cannot be performed. Electron microscopy is also not suited for the study of single point defects since it cannot resolve single atoms, the minimum cluster size resolvable being of the order of 10 to 100 atoms. There is some progress in field ion microscopy studies : they can resolve point defects, but their drawback is that they are bound to very special experimental conditions : they study surface atoms, not bulk atoms, and do so in very high electric fields. In recent time channeling experiments [34-36] have given some information on the location of SLD and diffuse scattering $\mathrm{X}$-ray measurements $[37,38,26]$ on the geometric structure of SLD.

However, most of the microscopic information on SLD in metals comes still from rather indirect evidence, as for instance studies of the temperature or concentration dependence of resistivity changes during irradiation or annealing.

We think, therefore, that in metals where other microscopic methods are still not extremely powerful, a method like the ME has a wide field of application on SLD.

This along with the facts that :

a) metals are the most frequently used hosts in implantation studies where certainly SLD are created ;

b) there is already plenty of macroscopic information on SLD available from macroscopic methods to compare with.

In non-monoatomic non-metallic solids as for instance in oxides but especially in complicated chemical compounds the consequences of irradiation are more complicated than in the metals. There are not only consequences of displacement collisions, but also of the ionizing effects of the irradiation and of aftereffects of the ionizing radioactive decay. There are still few theoretical studies of irradiation effects in such solids, except for simple ionic crystals. We shall not deal with the ME-SLD interaction in these sub- 
stances here, but refer to the review papers by Wertheim [14], Friedt and Danon [39] and Zahn et al. [40].

3.2 WHAT MAY WE HOPE TO LEARN ABOUT STRUCTURAL LATTICE DEFECTS FROM THE MÖSSBAUER STUDIES ? - A Mössbauer spectrum can show different components belonging to various sites of the Mössbauer atom with different neighbourhoods. From the hyperfine interactions and the Debye-Waller factor it is generally possible to define, which is the Mössbauer atom's site undisturbed by SLD and which are the defect-correlated sites. From the hyperfine parameters of the latter, conclusions on vacancies in the neighbourhood or on an interstitial position of the Mössbauer atom can be drawn. A neighbouring vacancy for instance, could decrease a magnetic hyperfine field at the Mössbauer atom's site and cause an electric field gradient leading to quadrupole splitting. An interstitial position could result in a higher electron density changing the isomer shift. Changes of the Debye-Waller factor are also to be expected in both cases. Thus, we can hope from the ME to get information on the symmetry, the electron density, the vibrational behaviour at the Mössbauer atom and the microscopic lattice structure in the neighbourhood of a Mössbauer atom when influenced by neighbouring SLD.

Among other experiments for instance the ME and NMR measurements of Stearns [41] and of Budnick [42] have shown that the influence of neighbouring atoms on the magnetic hyperfine field at the probe's site decreases rapidly with increasing distance following approximately the oscillating behaviour as predicted by RKKY theory. Things are similar with the Friedel oscillations in the electron density and therefore the isomer shift [43]. The «shortsightedness 》 of the ME is a great advantage for studying microscopic conditions. Yet, one should always be aware when performing ME studies of SLD that just because of this «shortsightedness » of the Mössbauer atom the ME is much less valuable for the investigations of damage that is statistically distributed over the sample ( $«$ locally uncorrelated $»)$ unless the defect concentration is very high.

There are other microscopic methods for the investigation of SLD originating in the same way as the ME from nuclear physics and related to the ME. That is they use nuclear radiation as a probe for solids which are light opaque. Such methods are the angular correlation studies of nuclear radiation, NMR, etc. which have recently also begun to attend to the influences of SLD [44]. We think that the ME can claim important advantages for SLD studies. Different lattice sites with different hyperfine parameters produce different Mössbauer lines although these lines may often overlap so that their separation may be difficult and their assignment not unique. The resolution for internal fields is worse than in PAC, but the ME contains additional information on electron density (isomer shift) and vibrational behaviour (Debye-Waller factor).

4. Influence of structural lattice defects on Mössbauer spectra. Mössbauer studies of structural lattice defects. - The two subjects given in the title cannot be easily separated from each other. In many investigations the SLD provide both difficulties for the ME studies and an interesting object of investigation at the same time. So it will depend on the experimentalist's preferences and experience whether he will try to exclude or neglect SLD in his ME studies since they perturb his pure case ME spectra or will try to study the SLD themselves with the $\mathrm{ME}$ as a promising new method. Often he will just try to make a virtue of necessity by studying now more or less intentionally the SLD, too.

We think, most conditions of a solid involving $\mathrm{ME}$ and SLD together using the Mössbauer atom as a probe for the SLD (not as an indicator for metallurgical changes produced by the SLD) can be reduced to two separate initial conditions, which are unfortunately often both existant at the same time leading to a complex situation :

(1) SLD are often created with or without the experimentalist's intention in the production or excitation process of a Mössbauer nucleus (Mössbauer source). This leads to SLD locally correlated with the Mössbauer nucleus (« correlated damage »).

Examples : a) All implantation ME studies;

b) Experiments, which excite the Mössbauer level by a nuclear process or by Coulomb excitation (these processes might be called « internal implantation »).

(2) Mössbauer atoms and SLD are produced in completely separate processes ( $«$ uncorrelated damage $»$ ) or (if in one process) no SLD correlated locally with the Mössbauer atoms are produced. Subsequent migration of the SLD can lead to local correlation by "trapping " of the SLD at the Mössbauer atoms if these are impurities. In the case of irradiation at low temperature $(T \simeq 4 \mathrm{~K})$ such a diffusion can be initiated by a heating-up of the sample after the end of the irradiation. These reactions can probably be better controlled than the conditions of group (1). They may, therefore, have some interesting future application. In case of « high-temperature » irradiation ( $T \simeq$ room temperature), SLD diffusion may occur during or immediately after the SLD production process.

Mössbauer experiments which definitely can detect the influence of statistically distributed SLD without having produced some local correlation between SLD and Mössbauer atoms during defect creation or by trapping will not be discussed in this paper.

4.1 «CORRELATEd CREATION》 OF Mössbauer NUCLEI AND STRUCTURAL LATTICE DEFECTS. - In metals and semiconductors since about 1965 there has been increased concern for «correlated radiation damage » effects in Mössbauer sources. This was mainly due to 


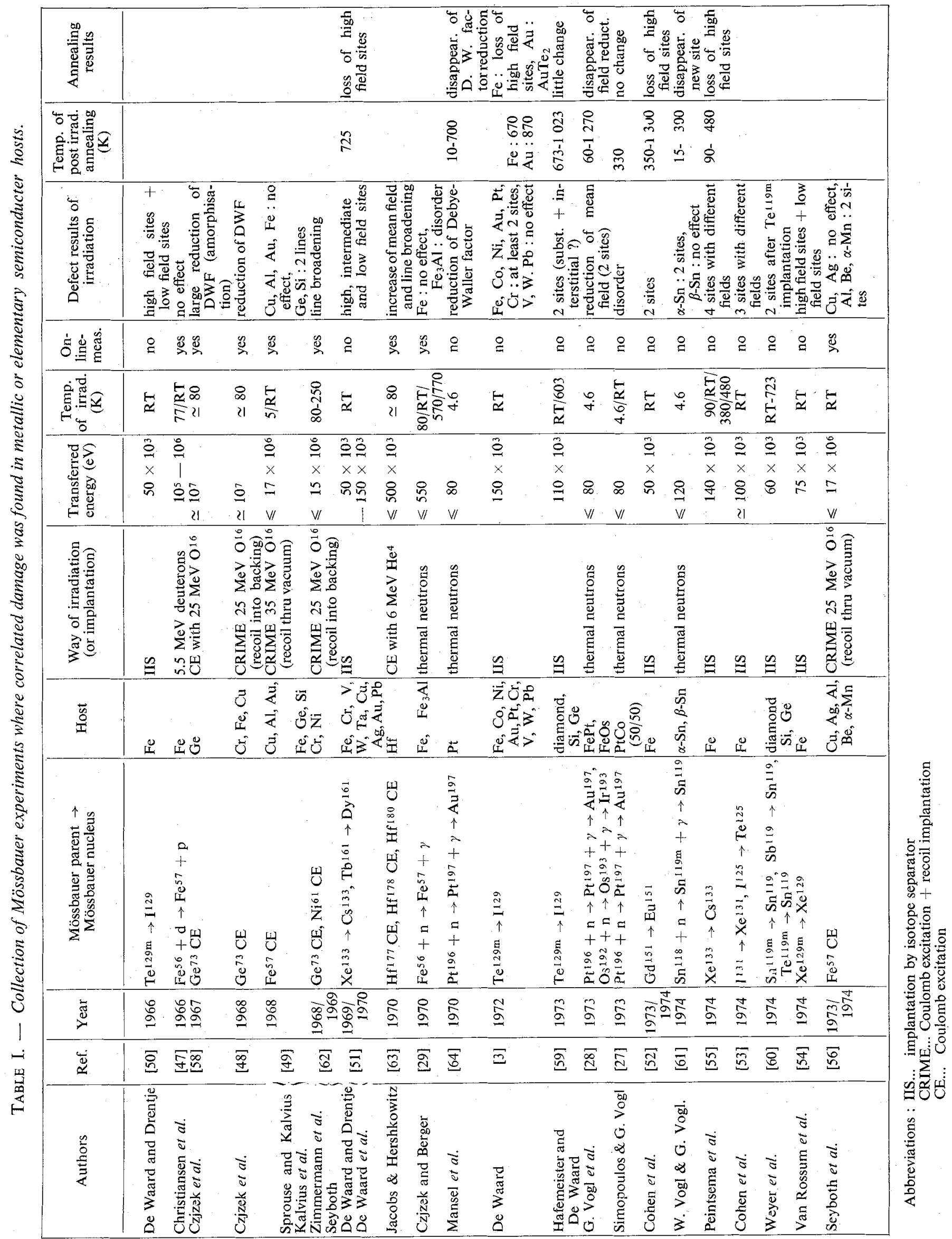


the development of new methods to excite Mössbauer levels as for example Coulomb excitation or $(d, p)$ reactions. Yet, in the beginning neither the group at John Hopkins [45], nor the Oak Ridge group [46] found clear evidence for radiation damage in metals in experiments or this type in spite of the high recoil energy from $\mathrm{Fe}^{57}$ of $\mathrm{Ni}^{61}$ excitation by $3 \mathrm{MeV} \alpha$ and $25 \mathrm{MeV} \mathrm{O}^{16}$ particles, resp.

These studies had been undertaken with the hope of finding $\mathrm{ME}$, and the authors were fortunate not to have found too much radiation damage. From about 1966 more thorough studies were performed with the aim of investigating possible SLD for their own sake. Several of these studies then found more than one site for the Mössbauer atom after irradiation or implantation.

Investigations performed since that time which pursued this aim are collected in Table I. The table contains the ME studies pertaining to SLD in metals, alloys and elementary semiconductors (diamond, silicon, germanium, $\alpha$-tin) of which the present author is aware. Regarding defect studies in compounds and ionic crystals the reader is referred to the papers [4, 39, 40].

By studying the table the following observations can be made :

4.1.1 The most frequently studied host metal is iron. Various methods to populate a Mössbauer level have been applied:

(1) $\mathrm{Fe}^{56}(\mathrm{~d}, \mathrm{p}) \mathrm{Fe}^{57}$ reaction $[47]$;

(2) $\mathrm{Fe}^{56}(\mathrm{n}, \gamma) \mathrm{Fe}^{57}$ reaction [29];

(3) Coulomb excitation and recoil implantation of $\mathrm{Fe}^{57}[49]$;

(4) ion implantation of a Mössbauer parent into iron by an isotope separator [50-55];

(5) doping of iron with a Mössbauer parent followed by an $(n, \gamma)$ excitation of the Mössbauer parent [28].

Methods (1), (2), (3) lead to on-line ME investigations. In methods (4) and (5) a Mössbauer parent (an impurity atom) is either implanted or doped into the iron lattice. Thus, the life time of the parent isotope provides a period of time after the production of the damage so that the ME can be studied after the end of irradiation; controlled defect annealing studies are also possible during this time interval. This great advantage is coupled with the drawback that in these cases the ME is studied at an impurity atom in the iron host.

4.1.2 The pure iron experiments (1-3) did not find significant SLD effect on the Mössbauer spectra (except for some influence on the Debye-Waller factor). The parent isotope studies (4-5) found such influence, namely clear evidence for vacancy neighbours of the implanted or recoil atom.

In the following we will discuss possible reasons for this difference.

First of all, a higher sensitivity for SLD is reached in annealing studies comparing Mössbauer measurements at the same sample before and after full defect recombination than in on-line experiments where Mössbauer measurements at different samples are compared. Also the resolution is generally rather weak in on-line experiments because of low counting rates, so that defect influences might sometimes have been missed.

Secondly, in the $\mathrm{Te}, \mathrm{Xe}, \mathrm{Tb}, \mathrm{Gd}, \mathrm{I}$ implantation experiments in iron [50-55] several sites with different magnetic fields and different Debye temperatures have been found attributed partly to Mössbauer atoms without, with one, two or more next neighbour vacancies. Figure 7 illustrates as an example results

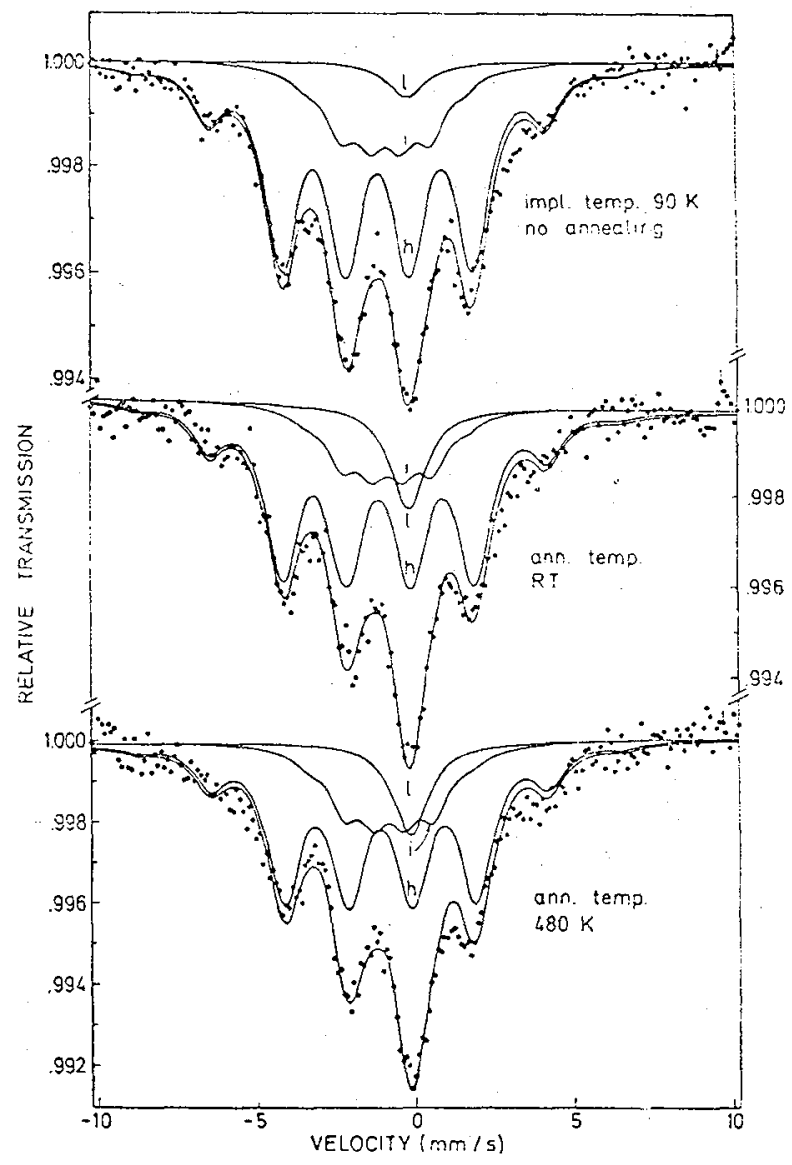

FIG. 7. - Mössbauer spectra of Xe $\mathrm{X}^{133}$ implanted at $90 \mathrm{~K}$ in iron and annealed subsequently to RT and $480 \mathrm{~K}$. Absorber : $\mathrm{CsCl}$ $T_{\mathrm{s}}=T_{\mathrm{A}}=4.2 \mathrm{~K} . h=$ high field component, $i=$ intermediate field component, $l=$ low field component. After Reintsema et al. [55].

of Reintsema et al. for $\mathrm{Xe}$ in iron [55]. We think the reason for this defect result is as follows : The mismatch of the Mössbauer atoms in the iron lattice is so large that the impurity retains ( $«$ traps ») vacancies in the cascade which would otherwise immediately recombine. Such trapping effects will be discussed in Section 4.2 in greater detail for interstitials. Such trapping certainly appears at sufficiently high temperatures where vacancies are mobile (above room temperature). At lower irradiation temperatures the « temperature » increase in 
the " spikes » could lead to vacancy motion, though estimates (Section 2.2) show this «temperature 》 to be rather too low $(\simeq 1000 \mathrm{~K})$ to permit vacancy motion during the short lifetime of a « spike» $\left(10^{-12}\right.$ to $\left.10^{-11} \mathrm{~s}\right)$. Nevertheless, this appears to be a possible explanation for the vacancy trapping at large impurities in iron.

In the iron-in-iron collisions (1-3) spontaneous relaxation of the defect structure and the consequence of the «temperature » in the «spikes» on the other hand may rather lead to defect recombination.

Finally, the (n, $\gamma$ ) excitation of a Mössbauer parent (e. g. $\operatorname{Ir}^{192}(\mathrm{n}, \gamma) \mathrm{Os}^{193}$ [28]) produces such low recoil energies that exchange collisions with near neighbours occur and the Mössbauer parent stops in the neighbourhood of the vacancy which remains at the Mössbauer parent's original site.

4.1.3 The results for metallic hosts other than iron though much fewer of them exist, are similar to the iron results.

In the aluminum host there is the interesting new result of Seyboth et al. reported at this conference [56] which might also allow the reinterpretation of the results of Kalvius et al. [49]. Figure 8 shows the results of both groups. In Seyboth's work $\mathrm{Fe}^{57}$ Coulomb

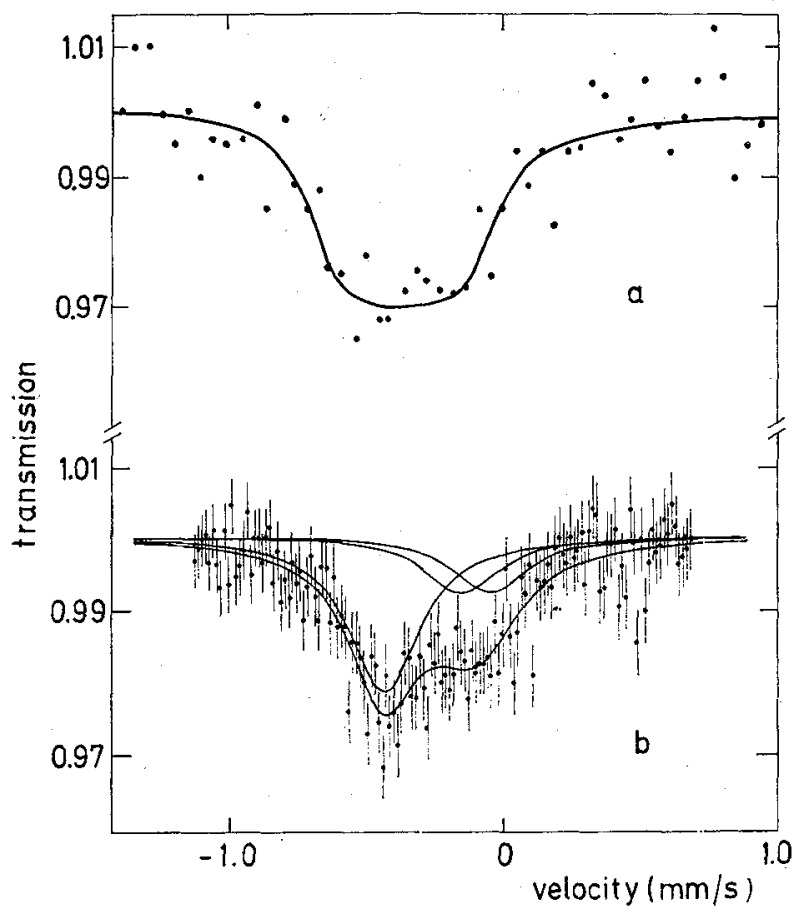

FIG. 8. - Mössbauer spectra of Coulomb excited Fe ${ }^{57}$, recoilimplanted at RT in aluminum. Absorber: enriched $\mathrm{Na}_{4} \mathrm{Fe}(\mathrm{CN})_{6}$, $\left.T_{\mathrm{s}}=T_{\mathrm{A}}=R T . a\right)$ After Kalvius et al. [49]. b) After Seyboth et al. [56].

implantation leads to the appearance of a new line, the corresponding Mössbauer parameters are in good agreement with the results of Mansel et al. [57] which are reported in the next section. It is proposed that in both cases the new line is due to iron atoms which form interstitial dumbbells with host atoms, though the production mechanisms of these dumbbells are different in the two cases. It should be noticed, that the mismatch of iron atoms in aluminum is particularly large since the iron atom is considerably smaller than the aluminum atom. This is the complementary situation to $\mathrm{Xe}$ or $\mathrm{Te}$ which are both much larger atoms than iron. In other hosts the appearance of such a new « interstitial line » was not found until now.

$4.1 .4(\mathrm{n}, \gamma)$ experiments in ordered alloys [27, 29] lead to disorder. Figure 9 shows as an example the Mössbauer spectra of an ordered CoPt alloy before

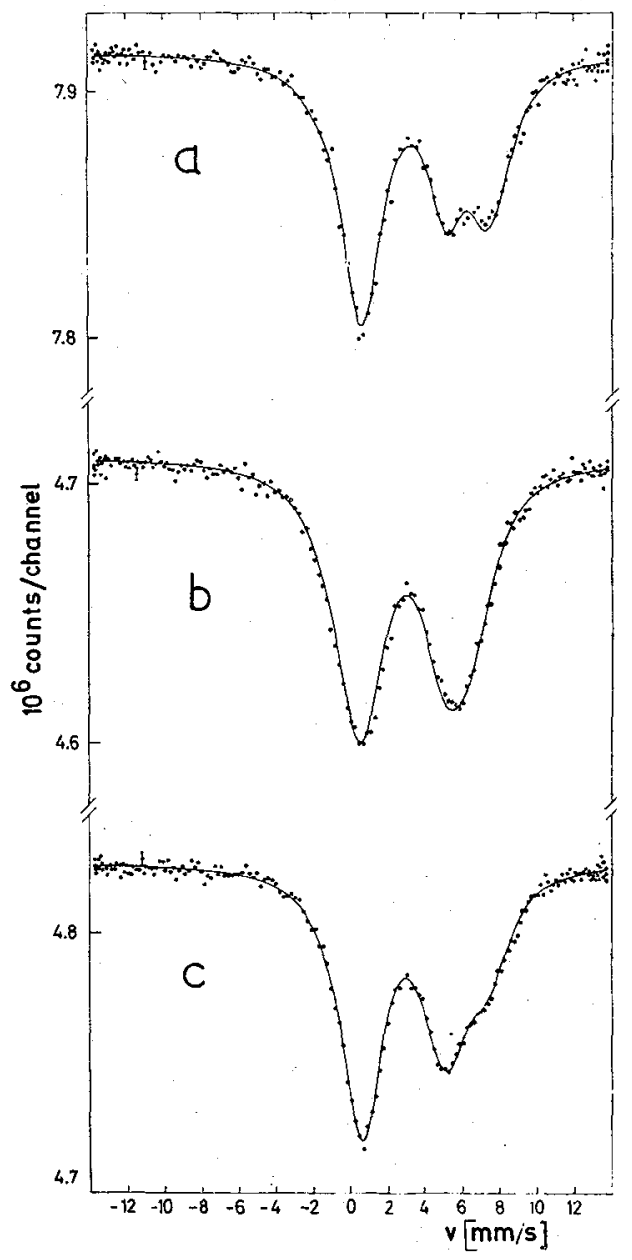

FIG. 9. - Mössbauer spectra of $\mathrm{Au}^{197}$ in the alloy 50 at. $\%$ $\mathrm{Co} / 50$ at. $\% \mathrm{Pt}: a$ ) ordered, $b$ ) thermally disordered, $c$ ) partially disordered by $(\mathrm{n}, \gamma)$ processes. Absorber : gold metal.

$T_{\mathrm{S}}=T_{\mathrm{A}}=4.2 \mathrm{~K}$. After Simopoulos and Vogl [27].

and after thermal neutron irradiation together with the spectrum of a thermally disordered alloy. The results are taken from Simopoulos and Vogl [27]. The results allow certain conclusions to be drawn on the recoil process which, however, shall not be reported here for the sake of brevity.

Thus, ordered alloys are perhaps the best candidates for investigations of the low-energy recoil processes, 
although some precaution may be reasonable in transferring their results to the processes in pure metals.

4.1.5 «Correlated radiation damage» studies in the elementary semiconductors with diamond lattice (diamond, silicon, germanium, $\alpha$-tin) all find the appearance of definite new Mössbauer lines [49, 58-61]. This means that in these semiconductors part of the recoil atoms find new « defect sites », either possibly interstitial or in a totally phase-transformed region $[58,61]$. Thus, semiconductors appear to be more sensitive to radiation damage than metals. We believe the reason to be partly that the diamond lattice has a more open lattice structure than the f. c. c. or b. c. c. metals, and partly the covalent bonding which - once broken does not regenerate immediately as does the metallic bonding. Thus, the recoil atoms can come to rest at interstitial sites or in a heavily disturbed lattice region, whereas they nearly always stop at substitutional sites in metals.

Summarizing the Mössbauer studies of correlated radiation damage one can say that in metals recoils rather seldom lead to positions of the recoiling atoms in a heavily damaged region, whereas in semiconductors they may do so. In metals the recoiling atom generally stops either in the neighbourhood of vacancies or at an undisturbed substitutional site. Only if the mismatch of the implanted or recoiling metal atom in the lattice is very big (iron in aluminum or xenon in iron) is there heavy damage in the vicinity of this atom.

4.2 UNCORRELATED PRODUCTION OF MÖSSBAUER NUCLEI AND STRUCTURAL LATTICE DEFECTS, BUT SUBSEQUENT LOCAL CORRELATION DUE TO TRAPPING PROCESSES DURING ANNEALING. - In Table II experiments are cited in which SLD were brought into the vicinity of the Mössbauer atom by migration, so that the
Mössbauer atom could serve as a probe for the defects. These experiments then cause a local correlation between Mössbauer atom and SLD not by a special creation process ( « correlated damage ») but by SLD migration followed by trapping of SLD by the Mössbauer impurity atom.

We shall now try to demonstrate the capability of the «trapping method " for creating a clear SLD situation by discussing the experiment of Mansel and Vogl $[57,65]$. It is thought that this experiment is the first from which one has achieved direct microscopic evidence for interstitial trapping and thus for interstitial diffusion.

The aim of this experiment was to create a situation in which the arrangement of SLD (interstitial atoms or vacancies) in the vicinity of a probe impurity atom (a Mössbauer atom) could be clearly controlled, and to study the influence of the lattice defects on the Mössbauer parameters at the impurity atom. This was obtained in the following way: A pure metal (aluminum, purity 99.999) was doped with very few impurity atoms (few ppm $\mathrm{Co}^{57}$ decaying to $\mathrm{Fe}^{57}$ ) on substitutional lattice sites. The uppermost spectrum in figure 10 shows the result of a Mössbauer measurement with the $\mathrm{AlCo}^{57}$ sample as the source : a single Mössbauer line appears (the splitting is caused by the pure iron absorber; only the two inner lines of the Zeeman sextett are shown). The sample was afterwards irradiated with fast neutrons at $4.6 \mathrm{~K}$, producing vacancies and interstitials.

The procedure was to periodically warm and isochronally anneal the sample at increasingly higher temperatures and, between each annealing treatment, to study the Mössbauer effect at $4.2 \mathrm{~K}$. During the gradual annealing treatment the defects diffuse in certain temperature intervals, according to their activation energy for migration. On their random walk the

\section{TABLE II}

Collection of Mössbauer experiments using the «trapping method» to cause local correlation of structural lattice defects and Mössbauer atoms

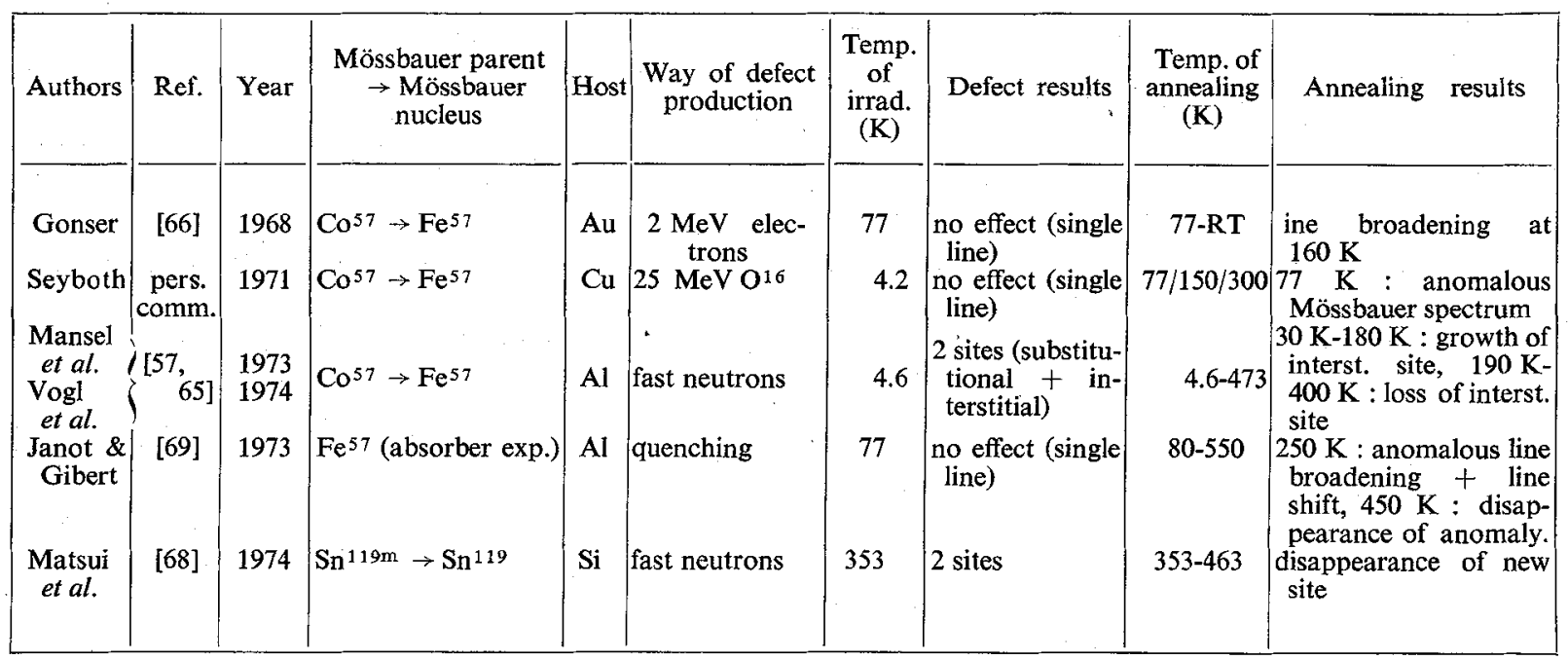




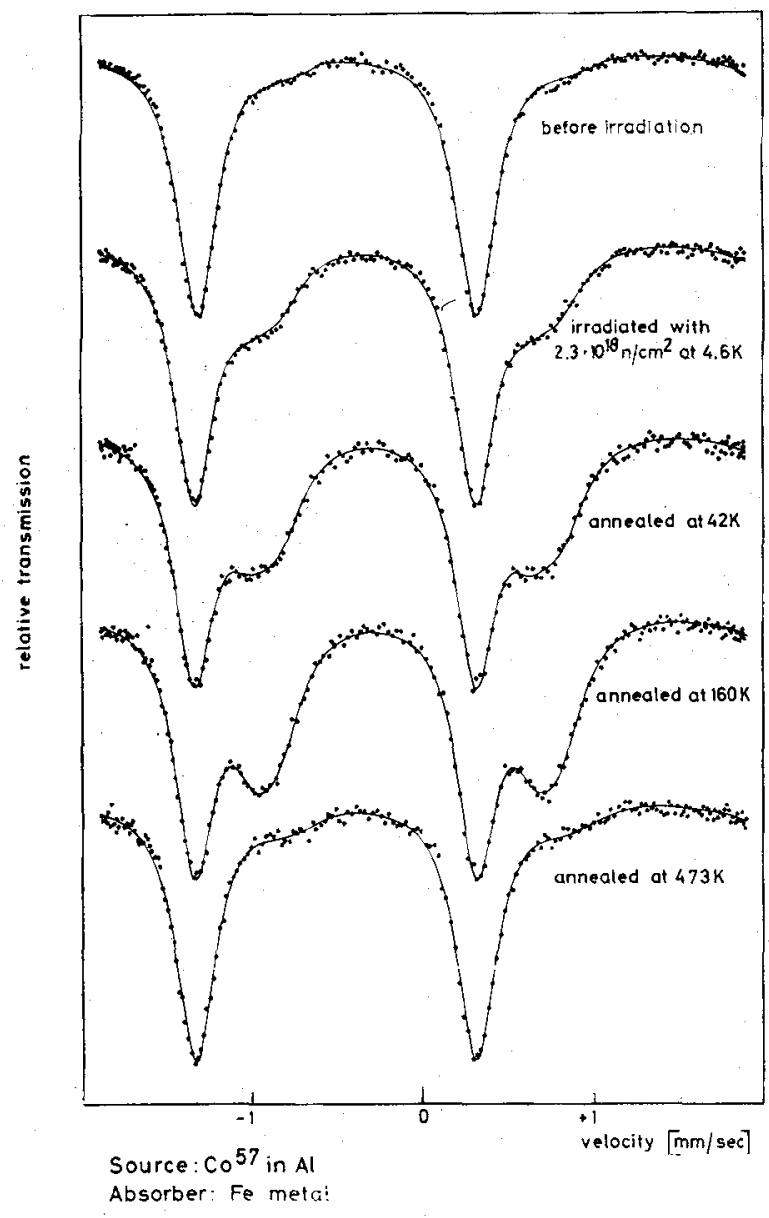

Fig. 10, - Mössbauer spectra of $\mathrm{Co}^{57}\left(\mathrm{Fe}^{57}\right)$ in aluminum before and after fast-neutron irradiation at $4.6 \mathrm{~K}$ and after subsequent isochronal annealing. Absorber : iron metal, causing magnetical splitting of the spectrum (only the 2 inner lines of the 6-line spectrum are shown). $T_{\mathrm{S}}=4.2 \mathrm{~K}, T_{\mathrm{A}}=77 \mathrm{~K}$. After Vogl et al. [65].

defects can be trapped at the impurities, if there is an attraction between defect and Mössbauer impurity atom. This will give rise to a signal in the Mössbauer spectrum.

Some characteristic results of the Mössbauer measurements after annealing are shown in the spectra of figure 10. A new Mössbauer line (« defect line ») appears which arises mainly on annealing between 30 and $45 \mathrm{~K}$, increases further up to $180 \mathrm{~K}$ and disappears again above $190 \mathrm{~K}$.

The features of the new line are that a change of the isomer shift against the original line of $+0.40 \mathrm{~mm} / \mathrm{s}$ is observed and also a quadrupole splitting of $\simeq 0.1 \mathrm{~mm} / \mathrm{s}$ is present. The change in the isomer shift corresponds to an increased electron density at the Mössbauer nucleus. This suggests that the cobalt impurities have trapped interstitials atoms which now require part of the lattice space formerly occupied by the cobalt atom.

Electrical resistivity measurements were performed simultaneously on the same sample. Figure 11 shows

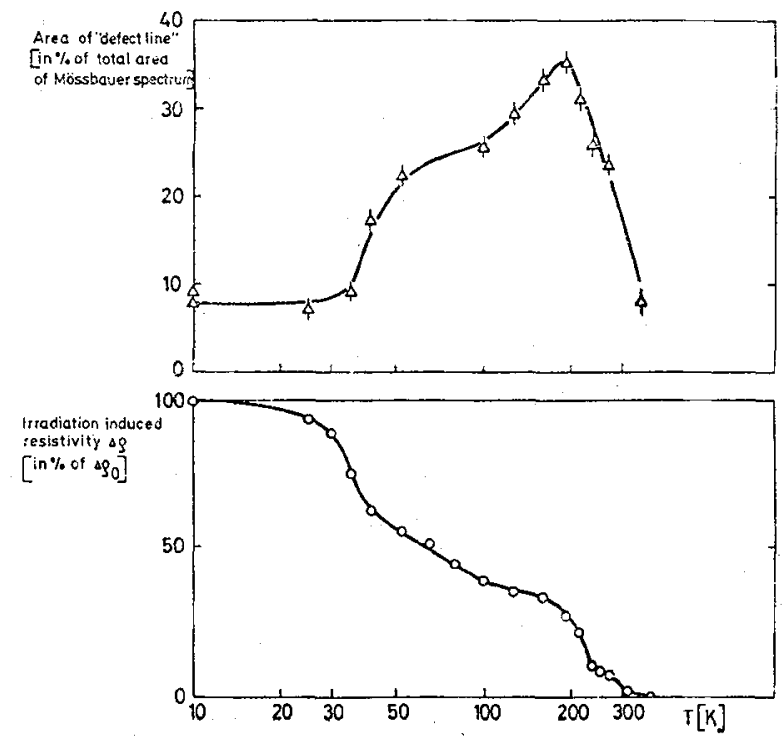

FIG. 11. - Comparison of the changes in the area of the $\mathrm{Co}^{57}\left(\mathrm{Fe}^{57}\right)$ Mössbauer « defect line » and in the electrical resistivity during isochronal annealing of aluminum irradiated at $4.6 \mathrm{~K}$ with about $2 \times 10^{17}$ fast neutrons $/ \mathrm{cm}^{2}$.

the results. The upper curve is a measure of the percentage of cobalt atoms having trapped defects during the gradual annealing, whereas the lower one gives the decrease of the irradiation induced resistivity in percent units of its value $\Delta \rho_{0}$ at the end of the irradiation. The "defect Mössbauer line » to a small extent has already been created during irradiation at $4.6 \mathrm{~K}$, suggesting interstitial trapping already during irradiation. It rises further in the temperature region of annealing «stage " $I$ in the resistivity (compare Fig. 6) which is ascribed, though from more indirect indications, to interstitial migration.

The coincidence of the stage in the resistivity and the increase in the Mössbauer area confirms that in this temperature region migrating interstitials can be trapped at impurities.

It might be interesting to compare this experiment with that of Swanson et al. [36] who concluded from channeling experiments on low-temperature irradiated aluminum that interstitials trapped at manganin impurities form $<100>$ dumbbells with the impurity atoms. Thus, the complex of cobalt impurity and interstitial aluminum atom may also have dumbbell configuration.

There have been precursors of the experiment by Mansel and Vogl. In 1968 Gonser [66] irradiated gold doped with $\mathrm{Co}^{57}$ with $2 \mathrm{MeV}$ electrons at $77 \mathrm{~K}$ and measured $\mathrm{ME}$ directly after irradiation and also after several heat treatments with gradually increasing temperature. He found some line-broadening upon reaching an annealing temperature of $160 \mathrm{~K}$. He attributed the line-broadening to interstitial trapping at the Mössbauer atom. In 1971 Seyboth $\left(^{1}\right.$ ) communicated with the author that after irradiation of $\mathrm{Co}^{57}$

(1) Sечвотн (personal communication) 1971. 
doped copper at $4.2 \mathrm{~K}$ and subsequent annealing at $77 \mathrm{~K}$ there appeared some indication of defects in the neighbourhood of the Mössbauer atoms. Unfortunately, it has not been possible to completely reproduce both these results, but they had given some indication for a promising experiment.

As a first application of the «trapping method» to microscopic investigations of lattice defects, the dynamic behaviour (the thermal vibrations) of the cobaltatom which forms an "interstitial complex » with a trapped aluminum interstitial was studied [65].

In the Mössbauer effect the thermal vibrations enter in the Debye-Waller factor (DWF) which can be written

$$
\mathrm{DWF}=\exp \left(-k^{2} \cdot<u^{2}>\right) \text {. }
$$

Here $k$ is the wave number of the Mössbauer $\gamma$ quantum and $\left\langle u^{2}\right\rangle$ is the average squared displacement of a Mössbauer atom in the direction of the emitted radiation.

Figure 12 shows the temperature dependence of the DWF between 4.2 and $140 \mathrm{~K}$. The upper curve is for

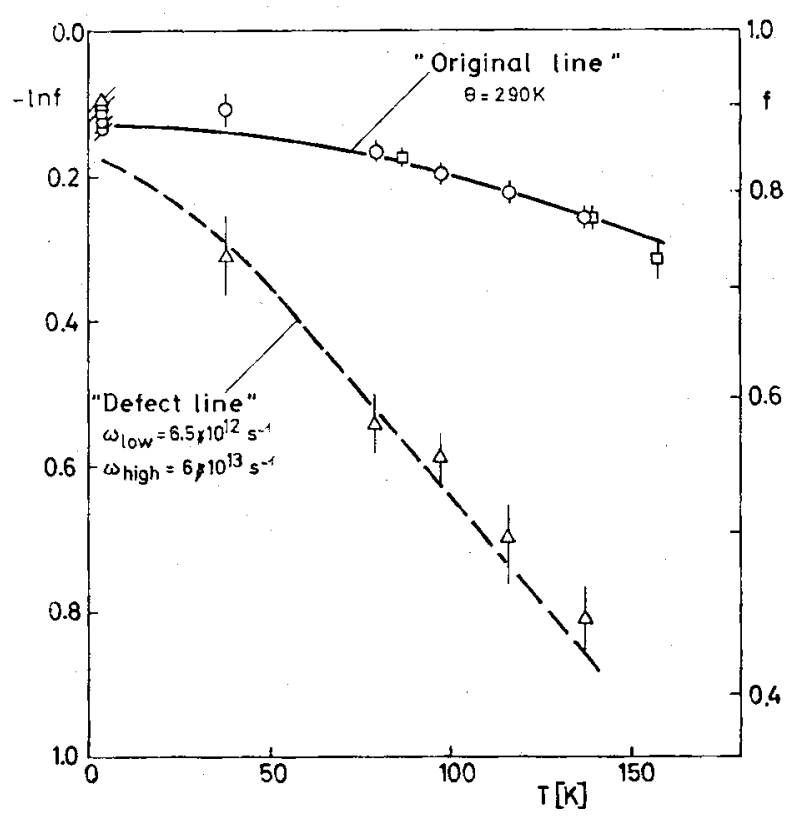

FIG. 12. - Debye-Waller factor of $\mathrm{Co}^{57}\left(\mathrm{Fe}^{57}\right)$ in aluminum. $\square$ « original line » in unirradiated sample, $O$ 《 original line » in irradiated sample, $\triangle$ « defect line » in irradiated sample. After Vogi et al. [65].

cobalt atoms on substitutional lattice sites-squares for pre-irradiation measurement, circles for those Mössbauer atoms, which even after irradiation have not trapped an interstitial. The squares and circles lying on the same curve indicate that these atoms do not feel an influence of the irradiation. The lower curve is for cobalt-atoms which have trapped interstitials. Here the temperature dependence of the DWF is much stronger. This means for example that at $140 \mathrm{~K}$

$$
\left.\left.<u^{2}\right\rangle_{\text {int }} \simeq 4<u^{2}\right\rangle_{\text {subst }} \text {. }
$$

The interstitial complex vibrates with a 4-times increased squared vibration amplitude at $140 \mathrm{~K}$. This may be the reason for the low activation energy for interstitial jumps into a neighbouring position which is the basic process for interstitial migration $\left({ }^{2}\right)$.

One can show that this strong temperature dependence of the DWF according to

$$
\text { DWF } \propto \exp -\left\{\int \frac{D(\omega)}{\omega^{2}} \hbar \omega\left(\frac{1}{e^{\hbar \omega / k T}}-1+\frac{1}{2}\right) \mathrm{d} \omega\right\}
$$

corresponds to a strong shift of the vibrational density of states $D(\omega)$ to lower frequencies $\omega$. The simplest explanation for this finding is the appearance of a special interstitial vibration mode with a frequency

$$
\omega_{\text {low }}=(6.5 \pm 1.0) \times 10^{12} \mathrm{~Hz}
$$

that is $\omega_{\text {low }} \simeq 0.1 \omega_{\text {max }}$. This low-frequency vibration explains the strong temperature dependence of the DWF. To explain the absolute values of the DWF, too, one has to assume an additional high-frequency vibration with

$$
\omega_{\text {high }} \simeq 6 \times 10^{13} \mathrm{~Hz} \simeq \omega_{\max }
$$

This $\omega_{\text {high }}$ can only be determined rather crudely from this experiment.

Analytical calculations as well as computer simulations of Dederichs et al. [67], predict such low-frequency Einstein oscillations of interstitials in copper. If we now compare the trapping experiment with Dederichs' calculations (Fig. 13) we notice a rather good agreement.
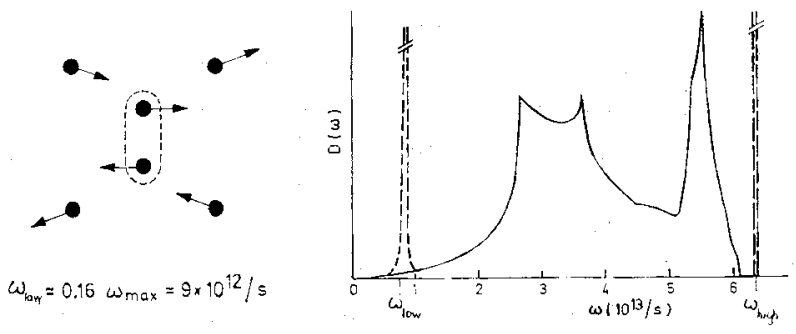

FIG. 13. - Simplified schematic representation of the vibrations of an interstitial dumbbell in aluminum. Left : Low frequency vibration of the interstitial dumbbell. Right: Full line : aluminum, broken line : interstitial vibrations. After Dederichs et al. [67].

A further important result is that the DWF results show these special interstitial modes to be rather localized. Cobalt atoms which have themselves trapped no interstitials after irradiation, experience no interstitial's influence on their thermal vibrations (circles in Fig. 12).

Very recently Matsui et al. [68] reported on $\mathrm{ME}$ studies of $\mathrm{Sn}^{119}$ in silicon as Mössbauer source after fast neutron irradiation at $80^{\circ} \mathrm{C}$. Whereas the Mössbauer spectrum before irradiation was a singlet, the

(2) Schilling, W. (personal Communication 1974). 
post-irradiation spectrum was broadened and shifted. Annealing between 110 and $190^{\circ} \mathrm{C}$ revealed the additional appearance of a new line shifted by +0.4 $\mathrm{mm} / \mathrm{s}$ corresponding to a decreased electron density. The additional line disappeared again on annealing at $190^{\circ} \mathrm{C}$. Matsui et al. attribute the new line to the trapping of irradiation-produced vacancies during their migrations at the tin impurities.

In experiments of the «correlated damage » type (Section 4.1) trapping of SLD at Mössbauer atoms may sometimes also be involved causing increased influences of SLD on Mössbauer spectra. Examples are to be found in the investigation of De Waard's group [51, 55], where apparently on annealing more vacancies can be trapped at the Mössbauer impurities in iron, causing a loss of vacancy-free high field sites.

There are two experiments which indicate that trapping of quenched-in vacancies at Mössbauer impurities can also lead to changes in the Mössbauer spectra. Janot and Gibert [69] found anomalous line broadening and a shift of the Mössbauer spectrum of $\mathrm{Fe}^{57}$ in aluminum quenched to $77 \mathrm{~K}$ when they warmed their sample up and reached the temperature region where vacancy migration is expected (250 to $300 \mathrm{~K}$ ). They interpreted these effects by an increase in electron density on the iron atoms when these «get» vacancies as first neighbours. The anomalous effects disappeared on further warming up above $450 \mathrm{~K}$. Sørensen and Cotterill $\left(^{3}\right)$ found similar effects in Mössbauer experiments at $\mathrm{Sn}^{119}$ and $\mathrm{Co}^{57}$ in aluminum.

Upon concluding this paragraph, we should like to stress that the «trapping method» appears to provide simpler and, therefore, clearer defect conditions than the " correlated damage method». This is because the migration kinetics of SLD have already been thoroughly studied with other methods. Thus, the «trapping method " should even be able to bring about information for the understanding of the «correlated damage».

5. Conclusion. - We hope to have shown in various examples that Mössbauer studies very often have to do with SLD. Our point was that this fact offers an excellent opportunity to study the SLD in a microscopic way. From these studies one gets microscopic information about the SLD which in metals is difficult to obtain from other methods.

Whereas until recently the SLD studies in metals and the solid state spectroscopy, belonging to two different fields of solid state physics, had little interaction with and knowledge of each other, this situation seems to be changing now. «Defect scientists» realize the promising possibilities of a microscopic method for gaining more detailed information on SLD. "Mössbauer people " on the other hand recognize a promising field of applications of the ME.

(3) Sørensen, K. O., Cotterill, R. M. J. (personal communication) 1973 .
We have stressed that in investigating SLD with the $\mathrm{ME}$ it is useful to create some near local correlation of SLD and Mössbauer atoms since the Mössbauer atom is mainly sensitive to influences from its immediate neighbourhood in a solid. There are mainly two possible ways of reaching this goal: « correlated damage » and trapping of SLD at Mössbauer impurities. The second method may sometimes give clearer results since it permits to some limited extent controlling the migration of SLD to the probe (the Mössbauer atom).

We think it very important to combine Mössbauer measurements with other methods, preferably methods sensitive to totally different defect properties. Promising attempts have been made combining ME and channeling or ME and electrical resistivity. Simultaneous measurements with various methods on the same sample are optimal.

What may be the most interesting future applications of the ME and related methods to the study of SLD ?

First, certainly the question about the final position of a particle externally implanted or knocked-on "internally implanted» in a solid might be answered in the most direct way by Mössbauer and related studies. Perhaps it is also possible to gain more insight into the consequences of the still rather obscure processes happening immediately after irradiation or implantation. By this we mean the atom movements due to the high energy dissipation in the displacement cascade leading to defect annihilation and clustering even at a temperature of zero $\mathrm{K}$ of the surrounding lattice. In this context the study of radiation produced disorder in ordered substances may be promising.

Secondly, with the ME we may hope to gain information about several properties of SLD which are not accessible to the conventional methods as e. g. the electrical resistivity. We have demonstrated this in Section 4.2 with a Debye-Waller factor study of the vibrational behaviour of an interstitial complex. The hyperfine interactions visible with the $\mathrm{ME}$ and related methods contain plenty of information about the local surrounding of the probe atom including SLD. Their explanation in terms of microscopic conditions is not yet very clear since there is still a need for more experimental data and above all for theories. But we hope that these theories will develop when enough clear experimental data becomes available.

The effort (experimentally and theoretically as well) is rewarding, since the illumination of the microscopy of lattice defects serves a field which is not only interesting in itself but also of great technological importance for the future nuclear reactor development where severe radiation damage problems will arise.

Acknowledgment. - The author gratefully acknowledges numerous valuable discussions and cooperation throughout the experiment discussed. in Section 4.2 with W. Mansel. He would like to thank Prof. H. Vonach for his constant supporting interest in this work, 
Prof: M. Kalvius as well as Dr. W. Vog1 for a number of helpful discussions, Dr. K. Böning for critically reading the manuscript and Dr. L. Schwalbe for a critical reading and polishing up the English.

\section{References}

[1] SChroeer, D., LAMBE, R. L., SPENCER, C. D., in Mössbauer Effect Methodology, Vol. 7, ed. I. J. Gruverman (Plenum Press, New York) 1971, p. 3.

[2] GONSER, U., in Mössbauer Spectroscopy and its Applications (IAEA, Vienna) 1972, p. 89.

[3] De WaARD, H., in ref. [2], p. 123.

[4] Wertheim, G. K., in The Electronic Structure of Point Defects, ed. G. K. Wertheim, A. Hausmann, W. Sander (North-Holland, Amsterdam) 1971, p. 12.

[5] Wollenberger, .H. J., in Vacancies and Interstitials in Metals, ed. A. Seeger, D. Schumacher, W. Schilling, J. Diehl (North-Holland, Amsterdam) 1970, p. 215.

[6] Thompson, M. W., Defects and Radiation Damage in Metals (University Press, Cambridge) 1969.

[7] Robinson, M. T., in Radiation Induced Voids in Metals, ed. J. W. Corbett, L. C. Ianniello (USAEC, CONF710601, Washington) 1972, p. 397.

[8] Corbetr, J. W., Electron Radiation Damage in Semiconductors and Metals (Academic Press, New York and London) 1966.

[9] Seeger, A., Chick, K. P., Phys. Stat. Sol. 29 (1968) 455. Wollenberger, H., Frank, W., Seeger, A., Peisl, H., Naturwissenschaften 59 (1972) 337.

[10] Dautreppe, D., in Hyperfine Interactions in Excited Nuclei, ed. G. Goldring, R. Kalish (Gordon and Breach, New York) 1971, p. 3.

[11] Baluffi, R. W., Lie, K. H., Seidman, D. N., Siegel, R. W., in ref. [5], p. 125.

[12] Dienes, G. J., VineYard, G. H., Radiation Effects in Solids (Wiley, New York) 1957.

[13] Torrens, I. M., Robinson, M. T., in Interatomic Potentials and Simulation of Lattice Defects, ed. P. C. Gehlen, J. R. Beeler, Jr, R. I. Jaffee (Plenum Press, New York) 1972, p. 739.

Robinson, M. T., Torrens, I. M., Phys. Rev. B 9 (1974) 5008.

[14] Lindhard, J., Nielsen, V., Scharff, M., Thomsen, P. V., Kgl. Danske Videnskab. Selskab. Mat. fys. Medd. 33 (1963) No. 10.

[15] Kinchin, G. H., Pease, R. S., Rep. Progr. Phys. 18 (1955) 1.

[16] Lucasson, P. G., Walker, R. M., Phys. Rev. 127 (1962) 485. Maury, F., Vajda, P., Lucasson, A., Lucasson, P., Phys. Rev. B 8 (1973) 5489 ; 5506.

[17] Jung, P., Schilling, W., Phys. Rev. B 5 (1972) 2046. Jung, P., Chaplin, R. L., Fenzl, H. J., Reichelt, K., Wombacher, P., Phys. Rev. B 8 (1973) 553.

[18] Gibson, J. B., Goland, A. N., Mirgram, M., Vineyard, G. H., Phys. Rev. 120 (1960) 1229.

[19] Erginsoy, C., Vineyard, G. H., Englert, A., Phys. Rev. 133 (1964) A 595.

[20] Erginsoy, C., Vineyard, G. H., Shimizu, A., Phys. Rev. 139 (1965) A 118

[21] Beecer, J. R. Jr, J. Appl. Phys. 35 (1964) 2226 ; Phys. Rev. 150 (1966) 470.

[22] Sefger, A., in Radiation Damage in Solids (IAEA, Vienna) 1962, p. 101.

[23] HoLmes, D. K., in The Interaction of Radiation with Solids, ed. R. Strumane, J. Nihoul, R. Gevers, S. Amelinckx (North-Holland, Amsterdam) 1964, p. 147.

[24] Brinkman, J. A., J. Appl. Phys. 25 (1954) 961.

[25] Doran, D. G., Radiat. Eff. 2 (1970) 249.

Doran, D. G., BurnetT, R. A., in ref. [13], p. 403.
[26] v. GUERARD, B., Thesis (Technische Universität, München) 1974.

[27] Simopoulos, A., Vogr, G., Phys. Stat. Sol. (b) 59 (1973) 505.

[28] Vogl, G., Schaefer, A., Mansez, W., Prechtel, J., Vogl, W., Phys. Stat. Sol. (b) 59 (1973) 107.

[29] Berger, W. G., Fink, J., Obenshain, F. E., Phys, Lett. 25A (1967) 466.

Czjzek, G., Berger, W. G., Phys. Rev. B 1 (1970) 957.

[30] Riess, K., VogL, G., Verhandlungen d. Deutschen Phys. Ges. 6 (1972) 637.

RIESs, K., Diplomarbeit (Technische Universität, München) 1971.

[31] Schilling, W., Burger, G., IsEBeck, K., Wenzl, H., in ref. [5], p. 255

Schilling, W., Sonnenderg, K., J. Phys. F 3 (1973) 322.

[32] De WaARD, H., in ref. [44].

[33] SeEger, A., Mehrer, H., in ref. [5], p. 1.

[34] Davies, J. A., in Channeling in Solids, ed. D. V. Morgan (Wiley, New York) 1973, Chapter 11.

[35] Applications of Ion Beams to Metals, ed. S. T. Picraux, E. P. Eer Nisse, F. L. Vook (Plenum, New York) 1974.

[36] Swanson, M. L., Maury, F., Quenneville, A. F., Phys. Rev. Lett. 31 (1973) 1057.

SWanson, M. L., Howe, L. W., J. Nucl. Mat. (1974) in press.

[37] Ehrhart, P., Schilling, W., Phys. Rev. B 8 (1973) 2604.

[38] Ehrhart, P., Haubold, H.-G., Schilling, W., in Festkörperprobleme XIV (Advances in Solid State Physics) (Pergamon Vieweg) 1974, p. 87.

[39] Friedt, J. M., Danon, J., Radiochim. Acta 17 (1972) 173.

[40] Zahn, U., Potzel, W., WAGner, F. E., in Perspectives in Mössbauer Spectroscopy, ed. S. G. Cohen, M. Pasternak (Plenum Press, New York) 1973, p. 55.

[41] Stearns, M. B., Phys. Rev. 147 (1966) 439 ; B 4 (1971) 4069 ; B 4 (1971) 4081 .

[42] BUDNICK, J., in ref. [44].

[43] Anand, M. S., Agarwala, R. P., Phil. Mag. 26 (1972) 297.

[44] Proc. Int. Conf. on Hyperfine Interactions Studied in Nuclear Reactions and Decay, Uppsala 1974, ed. E. Karlson, R. Wäppling (to be publ. in Physica Scripta).

[45] Goldberg, D. A., Keaton, P. W., Lee, Y. K., Madansky, L., Walker, J. C., Phys. Rev. Lett. 15 (1965) 418.

Goldberg, D. A., Lee, Y. K., Ritter, E. T., Stevens, R. R. Jr, Walker, J. C., Phys. Lett. 20 (1966) 571.

[46] Seyboth, D., Orenshain, F. E., Czjzek, G., Phys. Rev. Lett. 14 (1965) 954.

[47] Christiansen, J., Recknagel, E., Weyer, G., Phys. Lett. 20 (1966) 46.

Christiansen, J., Hindenach, P., Morfeld, V., ReckNAGel, E., Riegel, D., Weyer, G., Nucl. Phys. A 99 (1967) 345.

[48] CzJzeK, G., Ford, J. L. C. Jr, Love, J. C., Obenshain, F. E., WeGENER, H., Phys. Rev. 174 (1968) 331.

[49] Kalvius, G. M., Sprouse, G. D., HanNa, S. S., in Hyperfine Structure and Nuclear Radiations, ed. E. Matthias, D. A. Shirley (North-Holland, Amsterdam) 1968, p. 686.

Sprouse, G. D., Kalvius, G. M., in Mössbauer Effect Methodology, Vol. 4, ed. I. J. Gruverman (Plenum Press, New York) 1968, p. 37.

[50] De WaArd, H., Drentje, S. A., Phys. Lett. 20 (1966) 38.

[51] De Waard, H., Drentue, S. A., Proc. R. Soc. A 311 (1969) 139. 
De WaArd, H., Schurer, P., InIa, P., Niesen, L., AgarWAL, Y. K., in ref. [10], p. 89.

[52] Cohen, R. L., Beyer, G., Deutch, B. I., Phys, Rev. Lett. (in press) ; in ref. [35], p. 361.

[53] Cohen, R. L., de WaArd, H., Reintsema, S. R., Drentje, S. A., J. Physique Collq. 35 (1974) C6.

[54] Van Rossum, M., Langouche, G., Pattyn, H., Dumont, G., Odeurs, J., Meykens, A., Boolchand, P., Coussement, R., I. Physique Collq. 35 (1974) C6.

[55] Reintsema, S. R., Drentje, S. A., Schurer, P., de WAARD, H., Radiat. Eff. (in press).

[56] Brzoska, B., Baumann, J., Jena, H., Seyboth, D., SonTHEIMER, F., 5th Int. Conf. on Mössbauer Spectroscopy, Bratislava 1973, in press.

Seyboth, D., Volland, U., Brzoska, B., BaumanN, J., SONTHeImer, F., WIMmer, K., $J$. Physique Collq. 35 (1974) C6.

[57] Mansel, W., Vogl, G., Koch, W., Phys. Rev. Lett. 31 (1973) 359.

[58] Czjzek, G., Ford, J. L. C. Jr, Obenshain, J. C, Phys. Rev. Lett, 18 (1967) 529.

[59] Hafemeister, D. W., de WaArd, H., Phys. Rev. B 7 (1973) 3014.
[60] Weyer, G., Deutch, B. I., Nylandsted-Larsen, A., Andersen, J. V., Nielsen, H. L., J. Physique Collq. 35 (1974) C6-297.

[61] VOGL, W., Thesis (Technische Universität, München) 1974. Vogl, W., Vogl, G., J. Physique Collq. 35 (1974) C6-321.

[62] Zimmermann, B. H., Jena, H., Ischenko, G., Kilian, H., Seyвoth, D., Phys. Stat. Sol. 27 (1968) 639.

SeYboth, D., Proc. R. Soc. A 311 (1969) 119.

[63] Jacobs, C. G. Jr, Hershkowitz, N., Phys. Rev. B 1 (1970) 839.

[64] Mansel, W., Vogl, G., Vogl, W., Wennzl, H., Barb, D., Phys. Stat. Sol. 40 (1970) 461.

[65] Vogl, G., Mansel, W., Vogl, W., J. Phys. F (in press).

[66] GoNSER, U., in ref. [5], p. 649.

[67] Dederichs, P. H., Lehmann, C., Scholz, A., Phys. Rev. Lett. 31 (1973) 1130

[68] Matsui, K., Hasiguti, R. R., Shoji, T., OhKawa, O., in Proc. Internat. Conf. on Lattice Defects in Semiconductors, Freiburg 1974.

[69] J ANot, C., Gibert, H., Phil. Mag. 27 (1973) 545.

[70] Sørensen, K. O., Cotterill, R. M. J., personal communication (1973). 